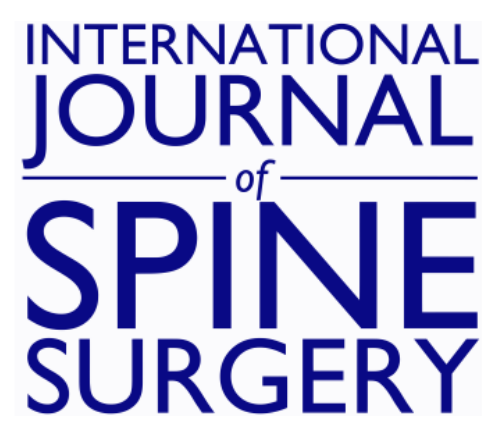

\title{
Endoscopically Guided Foraminal and Dorsal Rhizotomy for Chronic Axial Back Pain Based on Cadaver and Endoscopically Visualized Anatomic Study
}

Anthony Yeung and Satishchandra Gore

Int J Spine Surg 2014, 8 ()

doi: https://doi.org/10.14444/1023

http://ijssurgery.com/content/8/23

This information is current as of April 26, 2023.

Email Alerts Receive free email-alerts when new articles cite this article. Sign up at:

http://ijssurgery.com/alerts

The International Journal of Spine Surgery

2397 Waterbury Circle, Suite 1,

Aurora, IL 60504, Phone: +1-630-375-1432 


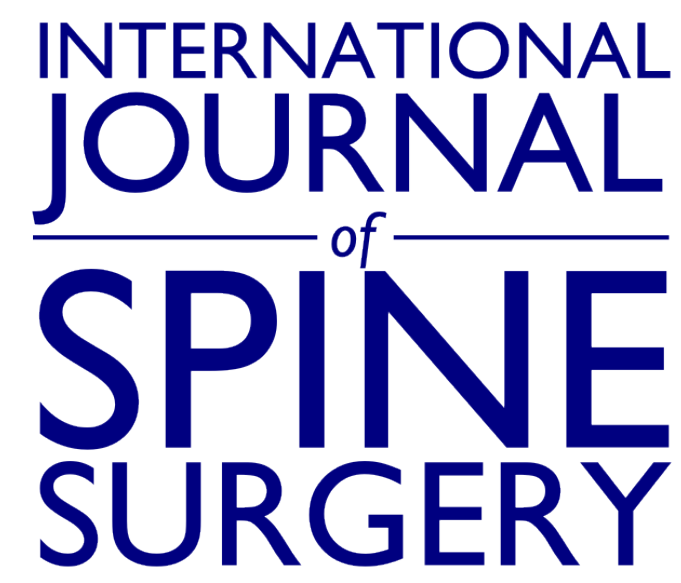

This article generously published free of charge by the International Society for the Advancement of Spine Surgery.

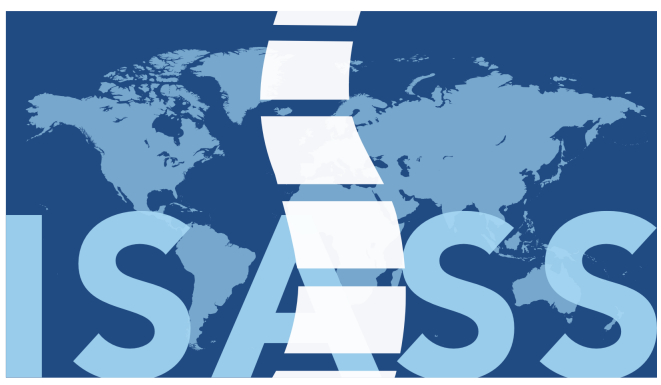

INTERNATIONAL SOCIETY for the ADVANCEMENT of SPINE SURGERY 


\section{Endoscopically Guided Foraminal and Dorsal Rhizotomy for Chronic Axial Back Pain Based on Cadaver and Endoscopically Visualized Anatomic Study}

Anthony Yeung, $M D,{ }^{1}$ Satishchandra Gore, $M D^{2}$

${ }^{1}$ Desert Institute for Spine Care, Phoenix, AZ, USA ${ }^{2}$ Prime Surgical Centre, Pune, India

\section{Abstract}

\section{Background}

Conventional fluoroscopically guided continuous radiofrequency (CRF) and pulsed Radiofrequency (PRF) lesioning of the medial branch, dorsal ramus, a standard technique to treat facet pain, is compared to an endoscopic visually guided technique. The endoscopic technique (Figure 1)is designed to ablate a larger area of the transverse process where the medial branch crosses to innervate the facet. Endoscopically guided visualization provides confirmation of nerve ablation or transection in the most common location of the branches of the dorsal ramus innervating the facet joint. 


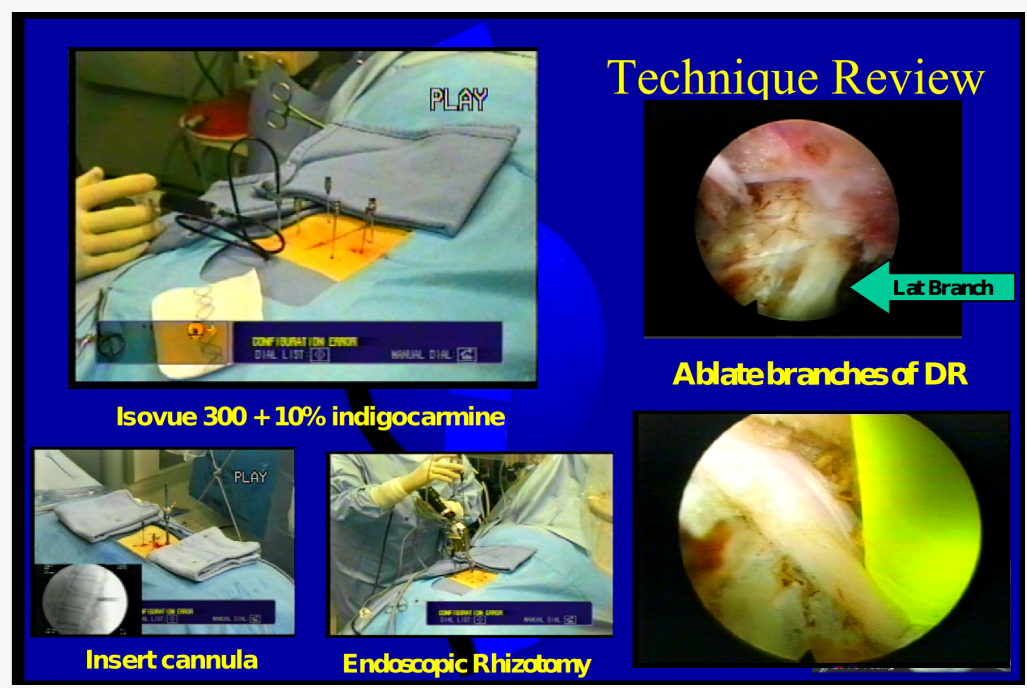

Fig. 1. Surgical setup for ablation of the medial, intermediate and lateral branches of the dorsal ramus.

\section{Materials and Method}

A retrospective non randomized study of 50 initial patients assessed the efficacy of endoscopic rhizotomy. Patients with lumbar spondylosis and facet arthrosis who had at least $50 \%$ pain relief by medial branch blocks met the inclusion criteria for the visualized, surgically directed endoscopic technique. A specially designed cannula and endoscope (Richard Wolf, GmBh) (Figure 2) was developed specifically for this purpose. After completion of the initial 50 patient pilot study in 2005, utilizing a low-temperature, ultrahigh frequency (1.7-4.0 MHz) bipolar energy radiofrequency source (Elliquence Int, Hewlett, NY) that demonstrated efficacy, 400 subsequent patients were added to this retrospective study by May 2013. The surgical technique refinement was guided by cadaveric variations observed from additional cadaver dissections (Figure 3 ) and endoscopic visualization of foraminal nerves that revealed variable locations of the dorsal ramus, including the medial branch. The anatomic variations supported a need for visualized rhizotomy. The inclusion criteria also involved increasing the percentage of back pain relief from medial branch blocks to a base of $75 \%$ estimated improvement in order to overcome the variable subjectiveness of a $50 \%$ improvement threshold that served to disappoint a small percentage of patients who overestimated the reported $50 \%$ improvement in hopes that they would qualify for the endoscopic guided procedure. 


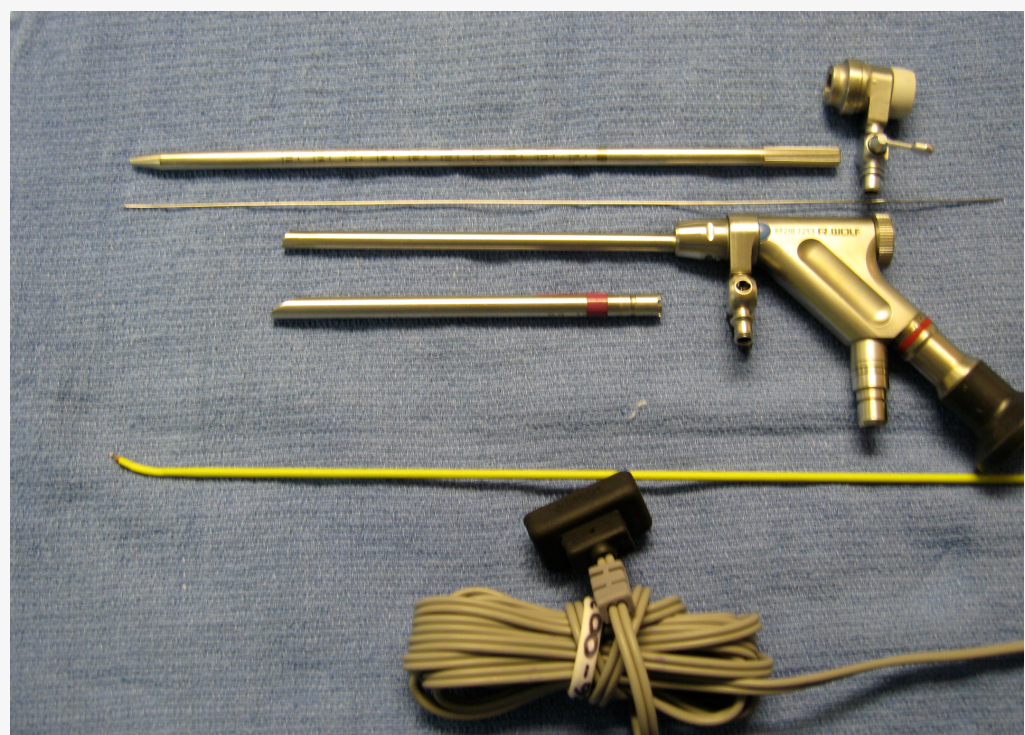

Fig. 2. Richard Wolf YESS Rhizotomy Set. The cannulas, endoscope, bitip and surgical bipolar RF probes by Elliquence are configured ergonomically to provide excellent focal length imaging to keep image in focus with the endoscope scope resting on cannula. The bitip probe cuts tissue, and the RF probe thermally ablates tissue efficiently.

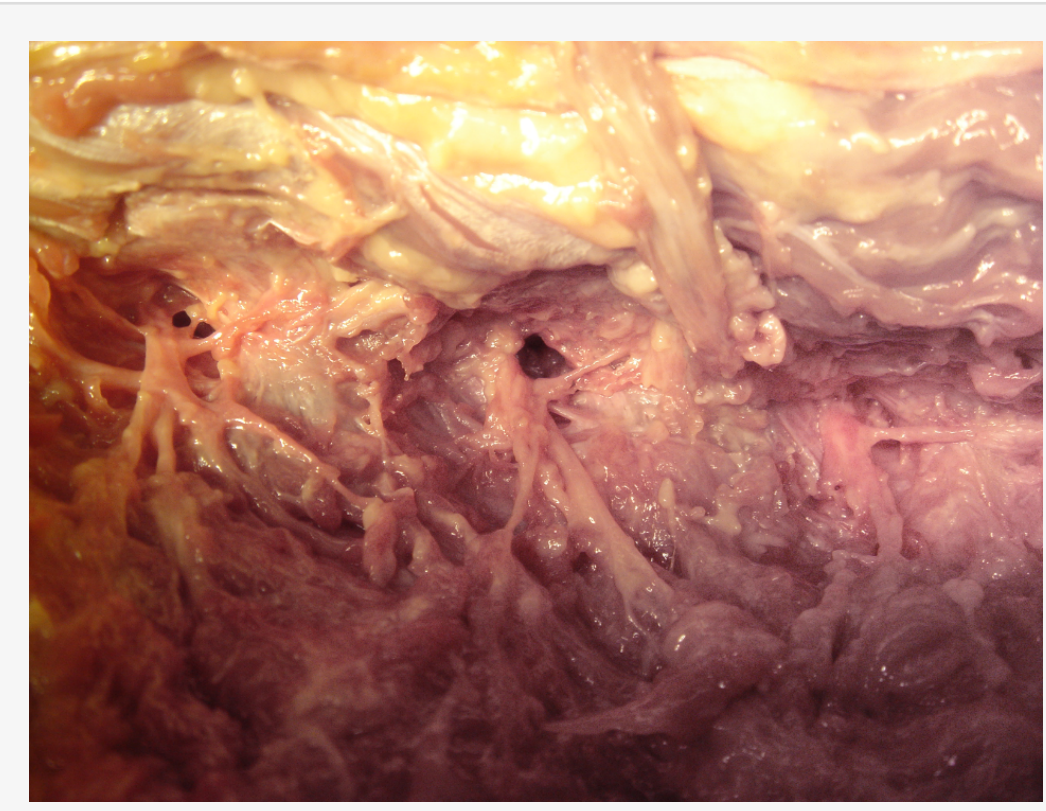

Fig. 3. Cadaver dissection of the dorsal ramus and its branches outlining the areas where branches of the dorsal ramus may be visualized and ablated before it reaches the facet joint.

\section{Results}

At one year follow-up in the initial study design, VAS improved 6.2-2.5, and ODI 48-28. All patients had VAS improvement equal or greater than injection. The results remained constant with additional surgical cases that continued to improve when technique and 
visualized rhizotomy allowed for greater surgical exploration and ablation of the targeted zone where more than just the medial branch could be ablated. Approximately 10 percent of the patients returned at one and two year follow-up with mild recurrence of their axial back pain, but none to the original level of pain. Additional rhizotomy of the upper lumbar facets provided additional relief in selected patients.

\section{Conclusions / level of evidence 3}

The cadaver studies demonstrated considerable variability in the location of the medial and lateral branches of the dorsal ramus. Variability was most common cephalad to L3-4. The dorsal ramus and its nerve branches can also be visualized in the foramen ventral to the intertransverse ligament. Neuromas and entrapment of the dorsal ramus has been identified endoscopically, and confirmed by $\mathrm{H}$ and $\mathrm{E}$ slides (Figure 4). In the upper lumbar spine, we were not able to find the medial branch to the facets consistently at same location. The nerve to the facet joint did not always cross the transverse process. Some branches enter the facet joint before crossing the transverse process adjacent to the tip of the SAP (Figure 5). The nerve can be mistaken for a furcal nerve or foraminal ligament. Nerve Ablation at above L3-4 levels may require lesioning of the dorsal ramus or targeting the nerve innervation on the facet wall, pedicle or capsule. 


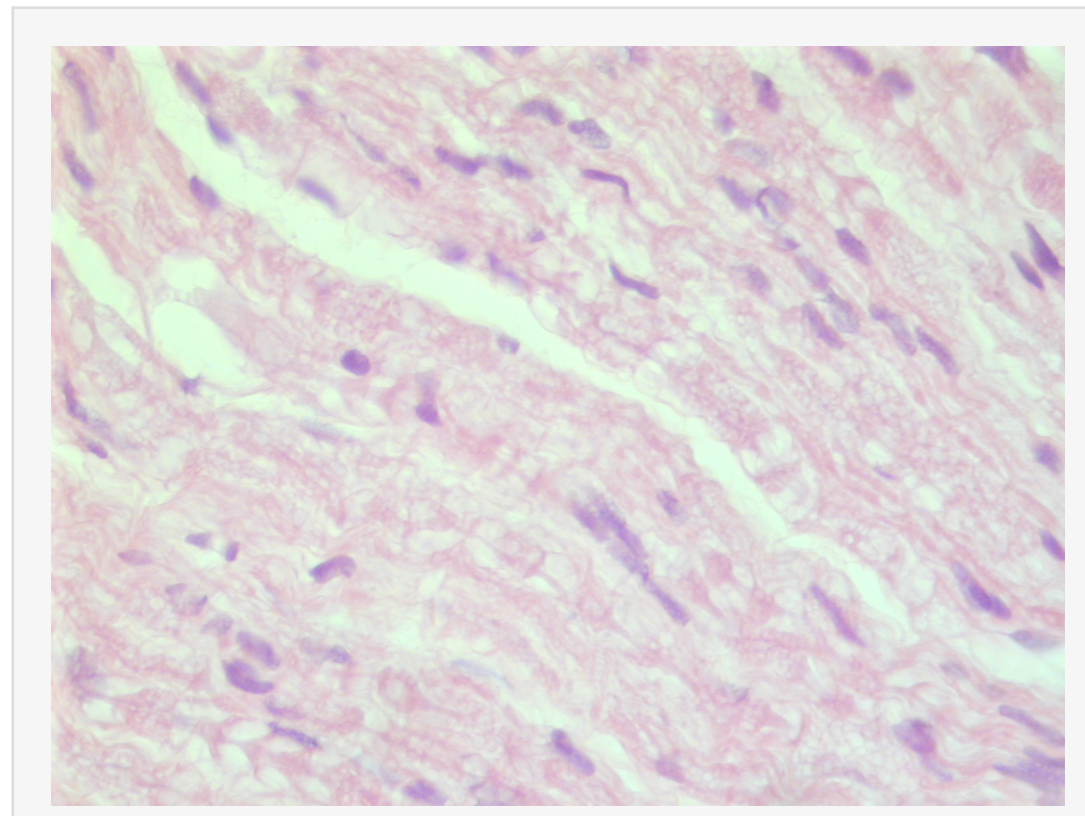

Fig. 4. This $\mathrm{H}$ and $\mathrm{E}$ slide of the biopsied specimen is consistent with a peripheral nerve fiber.

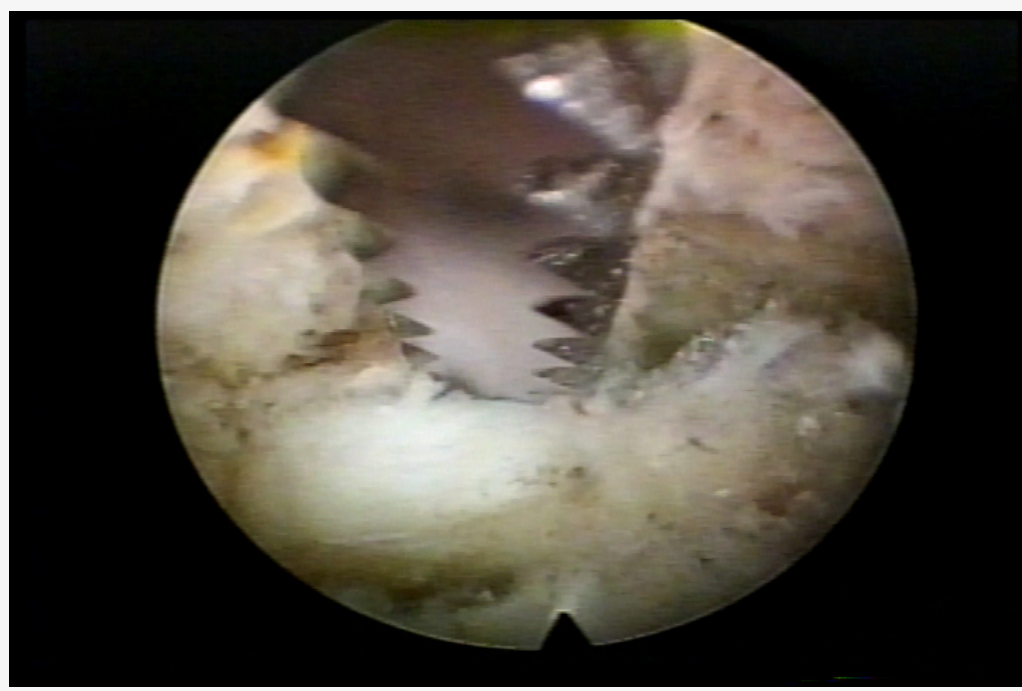

Fig. 5. This foraminal view of a branch of the dorsal ramus is in the foramen at the level of the SAP. The nerve runs along the ventral lateral aspect of the superior facet to the tip, and can also run in the vicinity of the foraminal ligament. Endoscopic rasps, trephines, kerrisons, and burrs can be used for foraminoplasty. The nerve should be preserved, if possible, but transection of a branch of the dorsal ramus contributes to axial back pain relief. Branches of the dorsal ramus originates in the foramen before exiting to traverse the transverse process. These nerves are difficult to differentiate from furcal nerves arising from the spinal nerves. Palpating the nerve using local anesthesia can sometimes demonstrate a pain response, but not always, depending on the level of sedation and anesthetic use.

\section{Clinical Relevance}


Endoscopically guided facet rhizotomy provides more consistent ablation of the medial and lateral branches of the lumbar dorsal ramus compared to radiographically guided pulsed radiofrequency. The variations in the location of facet innervation can explain the variability of clinical results in fluoroscopically guided RF lesioning. This observation dictates a need for visually guided MIS procedure for best results.

keywords: Endoscopic, rhizotomy, visualization

Volume 8 Article 23 - Endoscopic \& Percutaneous Special Issue doi: 10.14444/1023

\section{Introduction}

Continuous radiofrequency (CRF) and pulsed radiofrequency (PRF) lesioning of the medial branch of the dorsal ramus, an interventional surgical technique to treat facet mediated axial back pain, is a current method utilized in pain management for the treatment of chronic axial lumbar back pain. Clinically, even when successful, relief with flouroscopically guided radiofrequency lesioning may be only temporary and short lived. Armed with experience obtained from endoscopic foraminal surgery and a better understanding of the pathogenesis of low back pain, also aided by meticulous fresh cadaver dissection, a dorsal and foraminal Endoscopic Rhizotomy technique was developed to visually target the medial, intermediate and lateral branches of the dorsal ramus, or the dorsal ramus itself. It was demonstrated by our clinical results, observation and literature review that the dorsal ramus and its branches innervate not only the facet, but the soft tissues in the dorsal muscle column causing the involuntary list sometimes seen accompanying non-discogenic axial back pain to respond immediately to nerve blockage or rhizotomy. The pre-op involuntary list will immediately resolve following endoscopic rhizotomy.

\section{Materials and Method and Evolution of Inclusion Criteria}

A retrospective non-randomized pilot feasibility study was initiated in $2005^{1}$ to assess the effect of endoscopic radiofrequency lesioning of the medial branch of the dorsal ramus in patients with chronic axial back from lumbar spondylosis and facet arthrosis. Inclusion criteria for rhizotomy required at least 50\% improvement of their back pain with medial branch blocks to be eligible for endoscopic rhizotomy. Fifty patients were enrolled in the pilot study from March, 2005 through June, 2006. Follow-up was for a minimum of 1 year, maximum 22 months.

The medial branch block diagnostic protocol did not follow ISIS pain management guidelines. The senior author used a more robust test of a $10 \mathrm{cc}$ bolus of .5\% Marcaine mixed with $2 \mathrm{ml} 80 \mathrm{mg}$ of depomedrol (cocktail of $12 \mathrm{cc}$ total ). $2 \mathrm{cc}$ was then injected to 6 sites at 3 levels on the transverse process bilaterally under flouroscopic control. The larger bolus of anesthetic and steroid was used to represent a wider area affected by the block, and longer lasting pain relief to give a better assessment of the effect of the block that was also covered by the visualized endoscopic approach. It was not unusual for the patient to get weeks and even months of relief with this more robust block in terms of 
volume and area covered. The longer term relief due to use of steroids is acknowledged as contributing to pain relief, but this effect was viewed positively. If the use of steroids clinically improved the patient, rhizotomy was not recommended until the patient was unsatisfied with the time period of relief. The intent to recommend continued non-surgical treatment was suggested to place the patient's pain in perspective for the natural resolution of pain over time. If we did not use steroids, then the study would be used to only test for surgical candidates. This was not our clinical purpose, but its purpose was to get longer results augumented for the surgical study since steroids would theoretically enhance pain relief and benefit more prolonged relief in patient selection. Patients where told that if they at least months of relief, I would recommend continuing nonsurgical methods because of the lower risk / benefit / cost ratio.

After first 50 patients, the study was continued, with more stringent inclusion criteria to further restrict the recommendation for surgical intervention. It was also recognized that those patients who reported over 70\%-90\% relief from Medial branch blocks were consistently and more satisfied with their level of post-surgical pain relief. In spite of the more stringent inclusion criteria, the sample size gradually increased to 450 by the last review in 2013, using this stricter selection criteria. Patients who had evidence of degenerative disc disease, lumbar spondylosis, and facet arthrosis on MRI with predominant axial back pain, made worse with extension and rotation, including patients with adjacent level disease following fusion were also made eligible made for surgical treatment using the same selection criteria of significant relief from medial branch blocks.

\section{Results}

Forty-eight of the 50 from the initial pilot study was used to provide information for the design of an IRB approved cohort to more robustly determine patient inclusion criteria positive response would likely include the effect of medial branch blocks with and without steroid. 10 percent $(5 / 50)$ of the pilot study partially regressed at one year followup, but none were worse. None requested, nor received repeat rhizotomy the first year. Pre- and post-op VAS score decreased from 6.2 to 2.5 and Oswestry scores decreased from 48 to 28. No patient was worse. Duration of pain relief lasted over one year in the two year follow up period with ablation of more nerves in the vicinity of the transverse process lateral to the mammillary body. All were satisfied with their decision to have the rhizotomy even if some of the initial relief began to fade. Modified MacNab criteria was determined by the follow-up surgeon, into good, excellent or poor at the last visit prior to discharge, based the patient volunteering their satisfaction that they would return if their back recurred.

\section{Discussion}

While all had relief of back pain equal or greater than they had with the pre-operative block, some had relief of sciatica as well. The more patients undergoing visualized rhizotomy, and, as technical experience was obtained, other branches were visualized, including the intermediate and lateral branches of the dorsal ramus.

Following the initial 50 patient study, continuation of dorsal endoscopic rhizotomy became even more efficient as more branches of the dorsal ramus other than the medial branch was identified and ablated. Greater than 90 percent obtaining a level of injection 
relief equivalent or greater than the level obtained with the injection at post -op visit and by discharge was the usual result. We did not stratify the patients into separate groups, but acknowledge that to do so would provide more detailed information for clinical research purposes. That would be a weakness of the paper to correct in a follow-up, IRB approved prospective study. We plan on doing a prospective IRB approved study at the University of New Mexico endoscopic spine center at Sandoval with these parameters in mind.

The patients who did return, returned with recurrence of back pain; but when recurrent axial back pain occurred, some were found to have other new un related conditions such as HNP and spondylosis at another level.

Because of the excellent results from the pilot study, the second phase of the study evolved from visualizing additional nerves during visualized transverse and foraminal decompression. It was discovered that foraminoplasty also provided back pain relief. This resulted in further reviewing cadaver anatomy again and "tweaking" the initial inclusion criteria to combine foraminoplasty for foraminal stenosis combined with dorsal visualized rhizotomy in elderly patients with stenosis and lumbar spondylosis. This provided even more consistent and additional patient satisfaction with consistently predictable good/ excellent patient satisfaction ratings and the surgeon

Surgeon's own ratings of axial back pain relief. Probing under local anesthesia, we were also able to determine whether small non-painful nerves could be safely ablated. Therefore, minor variations and modifications of the surgical technique was done based on visualization and ablation of foraminal nerves recognized to be from the dorsal ramus and it's branches. We have also even seen what appeared to be neuromas in the foramen. Decompressing the neuroma, whether cut or freed can also give back pain relief. We now also look for nerve branches in the foramen during transforaminal disc decompression and foraminoplasty. We can safely ablate small nerves of $1 \mathrm{~mm}$ or less. This allowed more meticulous identification and ablation of the branches off the dorsal ramus and as well as the intermediate and lateral branches of the dorsal ramus, including releasing the inter transverse ligament and membrane to decompress the Dorsal Ramus.

Because of this observation, carefully selected patients with severe deformity and degenerative scoliosis who are high risk candidates for surgical correction due to age, increased surgical morbidity, or more risk for fusion, patients with adjacent level discogenic and non-discogenic axial back pain, and carefully selected workman's comp patients are now being offered the procedure obtaining equally successful pain relief from visualized rhizotomy. Preliminary results mirror the results of the pilot study in these selected patients. We have, by raising the bar for inclusion criteria for patients with facet block pain to pain relief of $75 \%$ or higher, get consistently greater patient satisfaction. There have been no patients in the disappointed, and not satisfied group when $70 \%$ or greater relief with medial branch blocks was used for surgical inclusion criteria. This is attributed to more accurate patient estimation of pain relief following medial branch blocks. As surgical experience, patient selection refinement, and experience with the endoscopic technique evolved, a continued study of cadaver dissection specimens of the dorsal ramus anatomy, guided by a literature review of spinal innervation, led to information on normal and variant anatomy that contributed to a more thorough clinical 
and surgical understanding of the complex innervation of the posterior spinal column. It also came with the realization that current fluoroscopically guided radiofrequency techniques had technical and anatomic limitations.

\section{Facet innervation}

As endoscopic decompression for HNP and foraminal stenosis also evolved, it was recognized that nerves in the foramen described as "furcal nerves" that some of these nerves were actually branches from the dorsal ramus. These nerves included the medial branch before it exited to cross the transverse process, that could be visualized (and ablated) transforaminally (Figure 6).

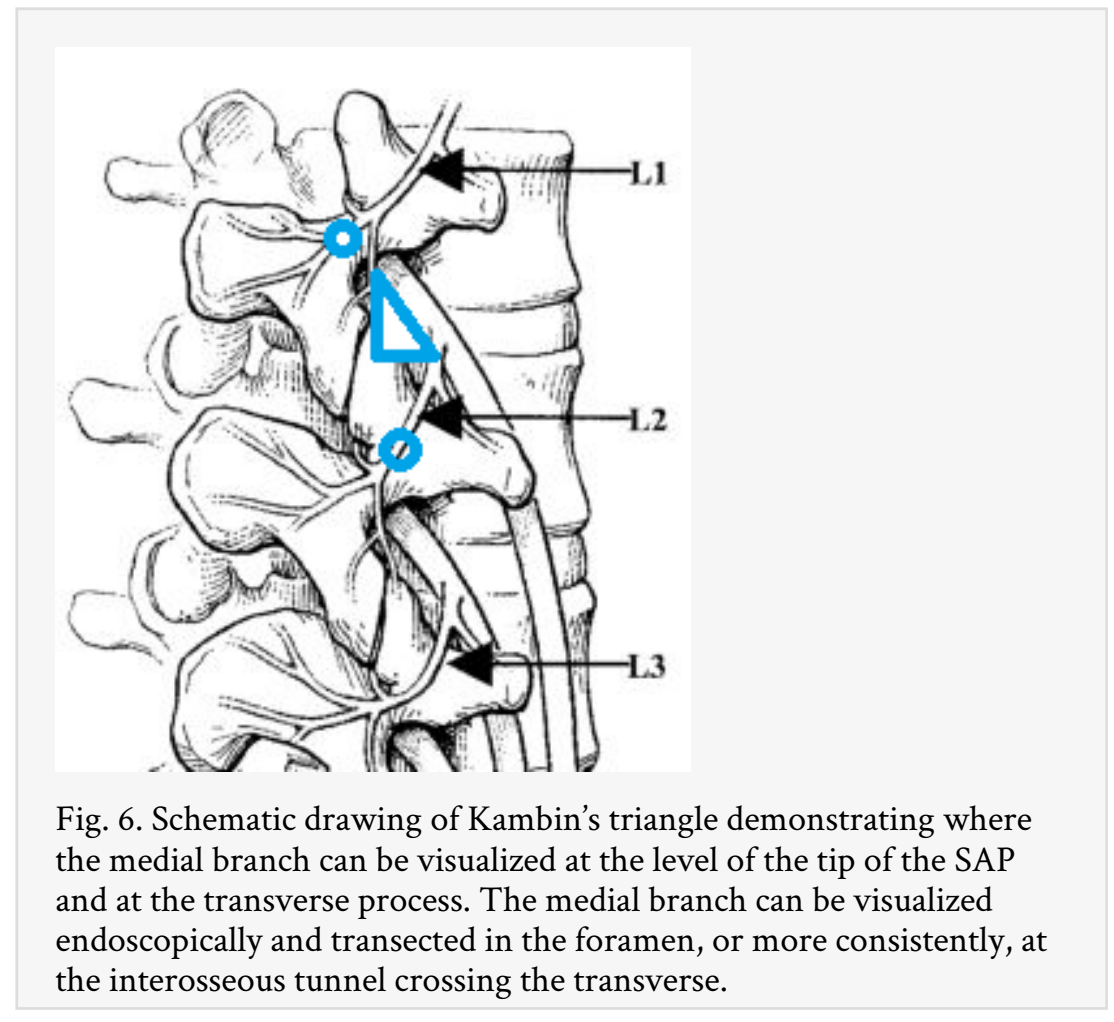

It was also determined that with stricter inclusion criteria of for patient inclusion, patients were consistently more satisfied at the first follow-up visit reporting as good or better pain relief if using a higher percentage and length of injection relief with steroid as the target for inclusion criteria. At a 50\% injection relief threshold for inclusion criteria, the patients were less able to estimate their percentage of pain relief. All, however, had some level of pain relief. One explanation for this is some patients wanted relief so badly that they may have over estimated their injection in order to get over the threshold for the procedure. It was also recognized that nerve branches visualized near the foraminal ligament, when ablated, also provided back pain relief. Review of the anatomy surmised that these were pure sensory nerves from the dorsal ramus, innervating the facet joints dorsally without crossing the transverse process. 
In a literature review, Mooney and Robertson described facet syndrome in 1976. They used radio graphically localized injection of steroids and local anesthetic into the facet joint as a diagnostic-therapeutic procedure. The facet joint was thought to be a persistent contributor to the chronic back pain in complaints of individuals with low back and leg pain $^{2}$

In 1982, Bogduk studied the anatomy of the lumbar mamillo-accessory ligament (MAL) and the branches of the dorsal ramus which enervated the facet at and below the disc segment level. The MAL bridges the mamillary and accessory processes of each lumbar vertebra and encloses the medial branch of the dorsal ramus in an osseofibrous tunnel. The tunnel maintains the proximal course of the medial branch in a constant relationship to bone. This constancy allowed for percutaneous techniques to stimulate, anesthetize or destroy the medial branch better than blinded RF ablation. The MAL is ossified in over $10 \%$ of lower lumbar vertebrae, and ossification may interfere with some percutaneous denervation techniques. ${ }^{3}$

The endoscopically guided targeting of the branches of the dorsal ramus would not only provide visual documentation of surgical rhizotomy, but will be able to expose the medial branch for ablation protected by the osseous tunnel.

The facet joints are not commonly the single or only primary source for low-back pain in the great majority of patients studied. It is a part of the degenerative process affecting the whole functional spinal unit. ${ }^{4}$ If we see a patient with axial back Age $>65$, pain relieved by lying down, pain not increasing by coughing, flexion, but increasing in rising from a flexed position, and aggravated by, extension and rotation, it may be related to the facet joint. ${ }^{5}$ Test to confirm the origin of facet pain is to relieve it by injection of the facet joint or the medial branch with local anesthetic. Controlled diagnostic studies have shown the prevalence of lumbar facet joint pain in only $27 \%$ to $40 \%$ of the patients with chronic low back pain without disc displacement or radiculitis, with a false-positive rate of $27 \%$ to $47 \%$ with a single diagnostic block. Datta, et al, published evidence for diagnosis of lumbar facet joint pain with controlled local anesthetic blocks as Level I or II-1. The level of evidence for therapeutic lumbar facet joint interventions was pegged at Level II-1 or II-2 for lumbar facet joint nerve blocks, and Level II-2 or II-3 evidence for radiofrequency neurotomy. ${ }^{6}$

Accepted pain management guidelines uses 50\% relief to select patients for denervation but more stringent criteria was thought to mar its utility. ${ }^{7}$ This observation was negated by our study. Uncontrolled medial branch blocks are superior to pericapsular blocks in selecting patients but both blocks work. If serial controlled blocks cannot be used, lumbar facet joint pain remains a diagnostic dilemma. ${ }^{8}$ Efficacy of denervation has been questioned in some studies. ${ }^{9}$ The authors found that an even greater percentage of good/ excellent results that exceeded or matched the pain relief from medial branch blocks led to nearly $100 \%$ patient satisfaction. It was a joint decision for rhizotomy dependent on the estimation at raised percentage of pre-op pain relief. 


\section{Indications and contraindications}

Imaging is usually utilized to determine whether the disc and other known pain generators can contribute to axial back pain as well. The location of the intermuscular cleavage plane between the multifidus and longissmus muscle provides surgical access to the branches of the dorsal ramus. ${ }^{10,11}$

\section{Complications}

In fluroscopically guided RF, denervation of the medial branch was associated with a $1 \%$ complication rate as sensory motor deficit for 2 or more weeks. ${ }^{12}$ The procedure, if done under endoscopically guided vision has no complications if proper protocol is followed, and the RF probe does not get ventral to the transverse process plane and does not penetrate the inter-transverse ligament. In our cases, when the thermal probe causes pain under local anesthesia, there can be a temporary dysesthesia only experienced in surgery or for a few hours or days post-op.

During the initial 50 patient study and subsequent 400 patients, temporary mild dysesthesia occurred only when the patient reported pain during the procedure and the surgeon noted inadvertent placement of the thermal probe ventral to the transverse process. We have had no permanent complications and no infections.

\section{Postoperative care}

The patient is under local anesthetic and mild sedation. Once the patient is comfortable. within a few hours he or she can mobilize. Mild oral pain relievers are given for a few days. The patient can be active but should avoid twisting the back and extension movement for about 2-3 weeks to allow for soft tissue healing. Core strength building exercises can be utilized to improve posture and mobility. There is no need for any postoperative imaging studies. Postoperative pain relief is judged on VAS and ODI.

\section{Outcome of flouroscopic radiofrequency by literature review}

Introduction of RF denervation was reported in 1975 by Shealy. In his study, 207 patients followed 6 to 21 months (mean 31 months), Relief of pain was achieved in 79\% of previously un-operated patients, in $41 \%$ of those with laminectomy but no fusion, and in $27 \%$ of those with an earlier fusion. No neurological complications were encountered. ${ }^{13}$ If we are able to identify that pain is of facet origin, then visualized endoscopic facet rhizotomy provides good / excellent results by Mac Nab criteria over $90 \%$ after 1 year follow-up. $10 \%$ have some pain returning after one year, but not to the index level. The patient can avoid a hardware assisted fusion in most of the cases. In summary, there is good evidence for the use of conventional radiofrequency neurotomy. ${ }^{14}$ RFD provides safe and significant short-term improvement in pain, analgesic requirements, function, satisfaction, and direct costs in patients with chronic LBP of facet origin. ${ }^{15}$ 
Among patients presenting with axial low back pain, facet arthropathy accounts for approximately $10-15 \%$ of cases. Facet interventions are the second most frequently performed procedures in pain clinics across the United States. Currently, there are no uniformly accepted criteria regarding how best to select patients for radiofrequency denervation. In this study it was suggested that using current reimbursement scales, proceeding to radiofrequency denervation without a diagnostic block is the most costeffective treatment paradigm. ${ }^{16}$ By multivariate statistical analysis, patients undergoing bilateral blocks for bilateral or axial symptoms were significantly more likely to achieve temporary relief, and to proceed to permanent denervation. There was no difference, however, between the long-term results of bilateral denervation for bilateral or axial pain and those of unilateral denervation for unilateral pain. There was no significant difference in the rate of response between the 56 patients who had undergone prior lumbosacral spine surgery and the 26 who had not in this report. ${ }^{17}$

Our results are at least comparable, but usually and more effective, with up to 8 year follow-up in our series. Both studies indicate that radiofrequency facet denervation is not a placebo and could be used in the treatment of carefully selected patients with chronic low back pain. ${ }^{18}$ Radiofrequency lumbar zygapophysial joint denervation results in a significant alleviation of pain and functional disability in a select group of patients with chronic low back pain, both on a short-term and a long-term basis. ${ }^{19}$ Large, prospective clinical audit as reported here indicates that proper patient selection and anatomically correct radiofrequency denervation of the lumbar zygapophysial joints provide long-term pain relief in a routine clinical setting. ${ }^{20}$ Comparison of Continuous RF and Pulsed RF suggests CRF is more effective and long lasting. ${ }^{21,22}$ The duration of effect may vary proportionally to the length of nerve coagulated. Techniques used to maximize the length of nerve within the radius of maximal heat include making multiple lesions, using larger needles, positioning the exposed needle parallel to the target nerve, and attempting more precise placement using 50 hertz test stimulation. A variation of the technique uses two needles that are simultaneously placed to lie parallel to one another and parallel to the probable area the target nerve is known to traverse. Heating both needles at the same time would be a faster method that theoretically might also include more tissue within the heating radius of the needle lengths. The more aggressive methods thus produce more lasting long term results. Heating the two electrodes sequentially was found to coagulate a wider area and thus likely to include a longer length of the target nerve and better results in less time. This coverage of large area was easily achieved by visualization and use of aggressive ablation. ${ }^{23}$

\section{Conclusion}

Our results suggest that a visualized endoscopic rhizotomy targeting the variable dorsal ramus anatomy provides more consistent and longer lasting results that the "gold standard" traditional fluoroscopically guided techniques.

The authors suggest a few helpful practical tips from experience:

1. The medial branch nerve is (more consistent, but not always) in the groove on side of the SAP crossing the transverse process. 
2. It may be covered with an osseous ligament that would require more effective ablation than by conventional RF techniques.

3. One joint has supply from 2 nerves one level above and same level so a bilateral 4 point surgery may be a norm.

4. The dorsal ramus and its branches can be ablated from the foramen before it gets to the transverse process. There are also branches that go to the facet from the foramen and there are branches that do not cross the transverse process, but traverse the facet wall and pedicle. It is difficult to see, and often stripped and ablated during foraminoplasty.

5. Foraminoplasty will likely involve ablation of branches of the dorsal ramus before they exit the foramen to the facet joint. Ablation of the nerves by the Superior articular process will provide axial back pain relief through rhizolysis in addition to foraminal decompression for sciatica.

When MIS surgical procedures are compared with fluoroscopically guided procedures, the incorporation of an endoscope makes it a surgical procedure that is minimally invasive and surgically effective. It bridges the gap between traditional open surgery and pain management techniques, but is enhanced by endoscopic visualization and guided surgically by appropriate surgical training principles.

\section{References}

1. Yeung, A."Endoscopic medial branch and dorsal ramus rhizotomy for chronic Axial back pain: a Pilot Study" International $25^{\text {th }}$ Jubilee Course on Percutaneus Endoscopic Spine surgery and Complementary Techniques." Zurich Switzerland January 24-25, 2007

2. Mooney V, Robertson J. The facet syndrome. Clin Orthop Relat Res. 1976 MarApr;(115):149-56.

3. Bogduk N. The lumbar mamillo--accessory ligament. Its anatomical and neurosurgical significance. Spine (Phila Pa 1976). 1981 Mar-Apr;6(2):162-7.

4. Jackson, Roger P MD, Jacobs Rae R MD Montesano Pasquale MD ++1988 Volvo Award in Clinical Sciences: Facet Joint Injection in Low-Back Pain: A Prospective Statistical Study. pg. 966-971

5. Revel M1, Poiraudeau S, Auleley GR, Payan C, Denke A, Nguyen M, Chevrot A, Fermanian J. Capacity of the clinical picture to characterize low back pain relieved by facet joint anesthesia. Proposed criteria to identify patients with painful facet joints. Spine (Phila Pa 1976). 1998 Sep 15;23(18):1972-6; discussion 1977.

6. Datta S1, Lee M, Falco FJ, Bryce DA, Hayek SM. Systematic assessment of diagnostic accuracy and therapeutic utility of lumbar facet joint interventions. Pain Physician. 2009 Mar-Apr;12(2):437-60.

7. Cohen SP1, Stojanovic MP, Crooks M, Kim P, Schmidt RK, Shields CH, Croll S, Hurley RW. Lumbar zygapophysial (facet) joint radiofrequency denervation success as a function of pain relief during diagnostic medial branch blocks: a multicenter analysis. Spine J. 2008 May-Jun;8(3):498-504.

8. Birkenmaier C1, Veihelmann A, Trouillier HH, Hausdorf J, von Schulze Pellengahr C. Medial branch blocks versus pericapsular blocks in selecting patients for 
percutaneous cryodenervation of lumbar facet joints. Reg Anesth Pain Med. 2007 Jan-Feb;32(1):27-33.

9. Leclaire R1, Fortin L, Lambert R, Bergeron YM, Rossignol M. Radiofrequency facet joint denervation in the treatment of low back pain: a placebo-controlled clinical trial to assess efficacy. Spine (Phila Pa 1976). 2001 Jul 1;26(13):1411-6; discussion 1417.

10. $\mathrm{Wu} \mathrm{H}, \mathrm{Fu} \mathrm{C}$, Jiang R, Yu WD. Multilevel magnetic resonance imaging analysis of multifidus-longissimus cleavage planes in the lumbar spine and clinical application to the Wiltse approach.Pak J Med Sci 2012;28(5):839-841

11. Vialle R, Court C, Khouri N, Olivier E, Miladi L, Tassin JL et al. Anatomical study of the paraspinal approach to the lumbar spine. Eur Spine J 2005; 14: 366-71.

12. Craig Kornick, MD, S. Scott Kramarich, MD, Tim J. Lamer, MD, and B. Todd Sitzman, MD, MPH Complications of Lumbar Facet Radiofrequency Denervation SPINE Volume 29, Number 12, pp 1352-1354 2004

13. Shealy CN. Percutaneous radiofrequency denervation of spinal facets. Treatment for chronic back pain and sciatica. J Neurosurg. 1975 Oct;43(4):448-51.

14. Falco FJ1, Manchikanti L, Datta S, Sehgal N, Geffert S, Onyewu O, Zhu J, Coubarous S, Hameed M, Ward SP, Sharma M, Hameed H, Singh V, Boswell MV. An update of the effectiveness of therapeutic lumbar facet joint interventions. Pain Physician. 2012 Nov-Dec;15(6):E909-53.

15. Burnham RS1, Holitski S, Dinu I. A prospective outcome study on the effects of facet joint radiofrequency denervation on pain, analgesic intake, disability, satisfaction, cost, and employment. Arch Phys Med Rehabil. 2009 Feb;90(2):201-5.

16. Cohen SP1, Williams KA, Kurihara C, Nguyen C, Shields C, Kim P, Griffith SR, Larkin TM, Crooks M, Williams N, Morlando B, Strassels SA. Multicenter, randomized, comparative cost-effectiveness study comparing 0,1 , and 2 diagnostic medial branch (facet joint nerve) block treatment paradigms before lumbar facet radiofrequency denervation. Anesthesiology. 2010 Aug;113(2):395-405.

17. North RB1, Han M, Zahurak M, Kidd DH. Radiofrequency lumbar facet denervation: analysis of prognostic factors. Pain. 1994 Apr;57(1):77-83

18. Nath S1, Nath CA, Pettersson K. Percutaneous lumbar zygapophysial (Facet) joint neurotomy using radiofrequency current, in the management of chronic low back pain: a randomized double-blind trial. Spine (Phila Pa 1976). 2008 May 20;33(12):1291-7; discussion 1298.

19. van Kleef M1, Barendse GA, Kessels A, Voets HM, Weber WE, de Lange S. Randomized trial of radiofrequency lumbar facet denervation for chronic low back pain. Spine (Phila Pa 1976). 1999 Sep 15;24(18):1937-42.

20. Gofeld M1, Jitendra J, Faclier G. Radiofrequency denervation of the lumbar zygapophysial joints: 10-year prospective clinical audit. Pain Physician. 2007 Mar;10(2):291-300.

21. Tekin I1, Mirzai H, Ok G, Erbuyun K, Vatansever D. A comparison of conventional and pulsed radiofrequency denervation in the treatment of chronic facet joint pain. Clin J Pain. 2007 Jul-Aug;23(6):524-9.

22. Kroll HR, Kim D, Danic MJ, Sankey SS, Gariwala M, Brown M. A randomized, double-blind, prospective study comparing the efficacy of continuous versus pulsed radiofrequency in the treatment of lumbar facet syndrome. J Clin Anesth. 2008 Nov;20(7):534-7. doi: 10.1016/j.jclinane.2008.05.021. 
23. Richard Derby, MD, and Chang-Hyung Lee, MD The Efficacy of a Two Needle Electrode Technique in Percutaneous Radiofrequency Rhizotomy: An Investigational Laboratory Study in an Animal Model A Laboratory Investigation 2006;9;207-214.

\section{Disclosures}

Dr. Gore is a consultant to Karl Storz Germany. Dr. Yeung receives royalties on Wolf products (Rhizotomy Instrument Set, Endoscope System).

\section{Corresponding Author}

Dr. Anthony Yeung, 1635 E Myrtle Ave, Suite 400, Phoenix, AZ 85020; email: ayeung@sciatica.com.

Copyright (C) 2014 ISASS - International Society for the Advancement of Spine Surgery. To see more or order reprints or permissions, see http://ijssurgery.com. 